\title{
STUDI PENGARUH TEMPERATUR TEMPER TERHADAP SIFAT MEKANIK DAN KETAHANAN KOROSI PADUAN Fe-1,26AI-1,05C
}

\author{
Ratna Kartikasari \\ Jurusan Teknik Mesin STTNAS Yogyakarta \\ Jl. Babarsari No.1 Depok, Sleman, Yogyakarta Telp. (0274) 485390 \\ kartikafajar@yahoo.com
}

\begin{abstract}
ABSTRAK
Paduan Fe-Al-C merupakan paduan baru kandidat pengganti stainless steel konvensional, dimana unsur Al berperan menggantikan unsur mahal $(\mathrm{Cr})$ pada stainless steel konvensional. Penelitian ini bertujuan untuk mengetahui pengaruh temperatur temper terhadap sifat mekanik dan ketahanan korosi paduan Fe-1,26Al-1,05C. Bahan baku peleburan terdiri dari: scrap baja Mn rendah, Al murni dan Fe-C. Peleburan menggunakan dapur induksi frekwensi tinggi kapasitas $50 \mathrm{~kg}$ dengan alloying di dalam ladle. Austenitisasi sampai temperatur $900^{\circ} \mathrm{C}$ dilanjutkan dengan quenching dalam media air. Proses temper dilakukan pada temperatur $250^{\circ} \mathrm{C}, 300^{\circ} \mathrm{C}, 350^{\circ} \mathrm{C}, 400^{\circ} \mathrm{C}$ dan $450^{\circ} \mathrm{C}$. Pengujian yang dilakukan adalah foto struktur mikro, pengujian tarik, pengujian kekerasan dan pengujian korosi dalam media 3,5\% $\mathrm{NaCl}$ dengan metoda kehilangan berat. Hasil pengamatan struktur mikro menunjukkan bahwa paduan Fe1,26Al-1,05C as cast mempunyai struktur ferit dan perlit, kecenderungan pembentukan struktur ferit terjadi dengan semakin tinggi temperatur temper. Kekuatan tarik maksimum terjadi setelah hardening yaitu sebesar $82,7 \mathrm{~kg} / \mathrm{mm} 2$ dengan regangan tertinggi sebesar 47,2\% setelah temper $450^{\circ} \mathrm{C}$. Kekerasan tertinggi sebebesar 287,1 VHN terjadi setelah hardening. Hasil pengujian korosi menunjukkan bahwa laju korosi paduan 1,26Al-1,05C as cast akan menurun dengan semakin tinggi temperatur temper.
\end{abstract}

Kata Kunci: paduan Fe-Al-C, stainless steel konvensional, alloying, temper.

\section{PENDAHULUAN}

Stainless steel (baja tahan karat) merupakan paduan berbasis besi (Fe) dengan kadar cromium (Cr) paling sedikit 10,5\% (Shackelford, 1992). Fe-Cr-C adalah paduan baja tahan karat jenis feritik dimana Cr berperanan terhadap ketahanan korosi sekaligus berfungsi sebagai penstabil struktur ferit (Leslie, 1983). Keunggulan paduan jenis ini ditentukan oleh keberadaan unsur Cr. Kekurangan yang dimiliki oleh stainless steel adalah terutama pada mahalnya biaya produksi. Karena Cr merupakan material strategis dan mahal di banyak negara, dimana 95 \% cadangan Cr dunia hanya terdapat di Afrika Selatan dan Zimbabwe.

Berdasar pada alasan ekonomi dan strategi maka diperlukan upaya untuk menemukan paduan baru yang dapat menggantikan stainless steel konvensional. Diantara sistim paduan yang paling menjanjikan dapat menggantikan peran paduan Fe-Cr-C adalah paduan Fe-Al-C, dimana unsur Almenggantikan unsur Cr(Tjong, 1986 dan Wang, 1988). Unsur aluminium (Al), diketahui keberadaannya di dunia sangat melimpah, yaitu merupa- 
kan unsur terbesar ketiga di bumi dan harganya relatif murah (Shackelford, 1992) dan proses produksinya relatif mudah (Frommeyer, 2000).

Paduan Fe-Al-C merupakan kandidat yang menjanjikan untuk menggantikan beberapa jenis stainless steel konvensional pada aplikasi temperatur medium sampai tinggi(Huang, 2002). Paduan Fe-Al-C feritik menunjukkan sifat-sifat fisik, mekanik dan teknologikal, ketahanan korosi dan oksidasi, dan biaya bahan baku yang rendah (Kobayashi, 2005).

Paduan Fe-Al-C lightweight steel yang mengandung $\mathrm{Al}$ sampai 9\% menunjukkan penurunan densitas hingga 10\% lebih (Frommeyer, 2000). Sayangnya paduan Fe-Al$\mathrm{C}$ pada temperatur ruang menunjukkan gejala rapuh dengan nilai ketangguhan yang rendah (Jablonska, 2006). Baligidad (1996) melaporkan bahwa penambahan karbon pada Fe-Al dengan kadar Al antara 8,5-16\% akan menghasilkan paduan dengan kekuatan yang lebih tinggi dan machinability yang lebih baik(Baligidad, 1998). Paduan Fe-Al-C dikembangkan untuk aplikasi struktur pada temperatur sampai dengan 873K (Sikka et al., (1993) and Prakash et al., 1991), .

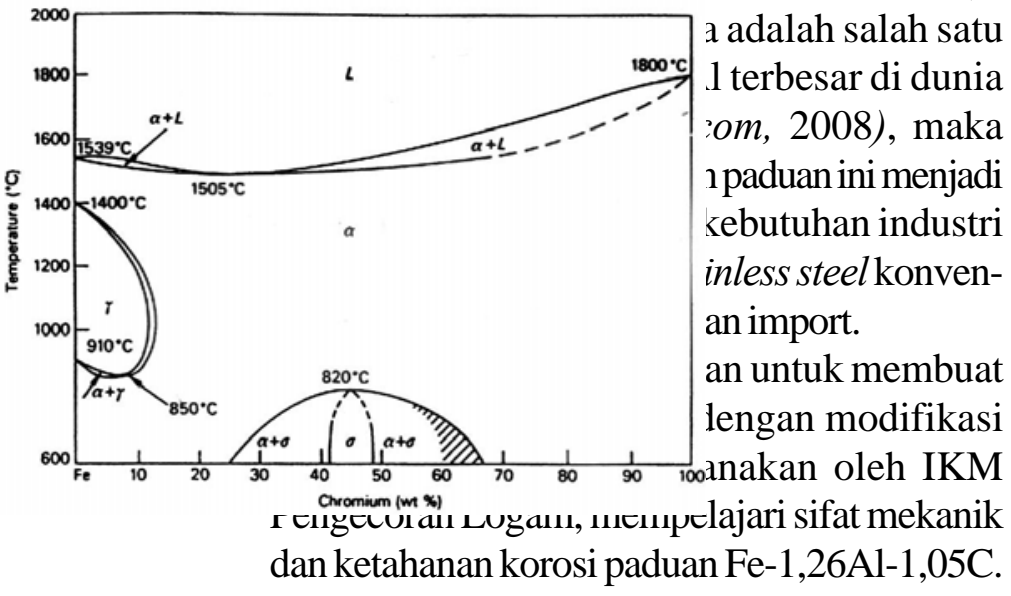

\section{TINJUAN PUSTAKA}

Untuk mengetahui pengaruh penambahan unsur dalam paduan biner terhadap fasa $\gamma$ yang dihasilkan, dapat mengacu pada daftar periodik unsur-unsur (Leslie, 1983). unsur-unsur yang berperanan sebagai pembentuk struktur ferit disebut sebagai Cr equivalent dan unsur-unsur yang berperanan sebagai pembentuk struktur austenit disebut sebagai Ni equivalent (Honey- combe, 1995) yang secara umum dirumuskan sebagai berikut : $\mathrm{Cr}$ equivalent $=(\mathrm{Cr})+2(\mathrm{Si})+$ $1,5(\mathrm{Mo})+5(\mathrm{~V})+5,5(\mathrm{Al})+1,75(\mathrm{Nb})+1,5(\mathrm{Ti})+$ $0,75(\mathrm{~W})$. Ni equivalent $=(\mathrm{Ni})+(\mathrm{Co})+0,5(\mathrm{Mn})$ $+0,3(\mathrm{Cu})+25(\mathrm{~N})+30(\mathrm{C})$

Hubungan antara $\mathrm{Cr}$ equivalent dan $\mathrm{Ni}$ equivalent digambarkan dalam diagram Schaeffler (Gambar 2).

Unsur paduan yang mempunyai perilaku seperti Cr dalam sistim paduan biner Fe-Cr adalah Al. Diagram kesetimbangan Fe-Al (Gambar 3) memperlihatkan kemiripan dengan diagram kesetimbangan Fe-Cr (Gambar 1) Dari daftar periodik unsur-unsur, juga dapat diketahui bahwa Al mempunyai gamma loop (loop g) seperti Cr.

Kelarutan $\mathrm{Al}$ dalam -Fe sangat kecil dibandingkan $\mathrm{Cr}$ (Avner, 1987). Hal ini berarti, Al hanya dapat ditambahkan dalam jumlah yang sangat terbatas.

Aluminium adalah logam reaktif yang dapat membentuk lapisan pelindung aluminium-oksida. Lapisan ini mempunyai sifat yang sangat stabil dalam lingkungan netral dan asam, tetapi rentan dalam lingkungan alkali (Fontana, 1988). Paduan $\mathrm{Al}$ (Al alloy) telah secara luas digunakan dalam industri, tetapi dalam stainless steel konvensional, Al hanya ditambahkan dalam jumlah yang kecil. Sistim paduan Fe-Al bersifat feritik pada semua temperatur (setara dengan Fe-Cr stainless steel). Fasa muncul dalam area yang sangat sempit pada penambahan Al dalam jumlah kecil $( \pm 2 \%)$ mulai temperatur $912^{\circ} \mathrm{C}$ sampai dengan $1394^{\circ} \mathrm{C}$.

Gambar 1. Diagram Kesetimbangan Fe-Cr (Leslie, 1983) 
Gambar 2. Diagram Schaeffler (Honeycombe, 1995) (Honeycombe, 1995)

Pada proses pendinginan lambat fasa $\gamma$ dalam sistim paduan yang mengandung $\mathrm{Al}$ rendah dan C tinggi akan terdekomposisi membentuk fasa eutektik. Sedangkan pada pendinginan cepat akan tertransformasi membentuk strukturmartensit.

Menurut Davidson dkk. (1988), penambahan Mn pada stainless steel konvensional dalam jumlah besar akan menurunkan sifat-sifat paduan, tetapi dalam jumlah yang sedang akan mempunyai pengaruh yang menguntungkan, karena Mn akan berinteraksi dengan S membentuk Mn-sulfida yang akan berperan dalam meningkatkan ketahanan korosi, khususnya terhadap pitting corrosion. Sistim paduan Fe dengan 28-30\% Mn, 8-10\% Al dan $0,8-1 \% \mathrm{C}$ di atas $850^{\circ} \mathrm{C}$ mempunyai struktur austenit lewat jenuh, dengan pemanasan $350-700^{\circ} \mathrm{C}$ struktur austenit akan terdekomposisi membentuk fasa (Fe,Mn)3AlC yang akan meningkatkan kekuatan luluh secara signifikan.

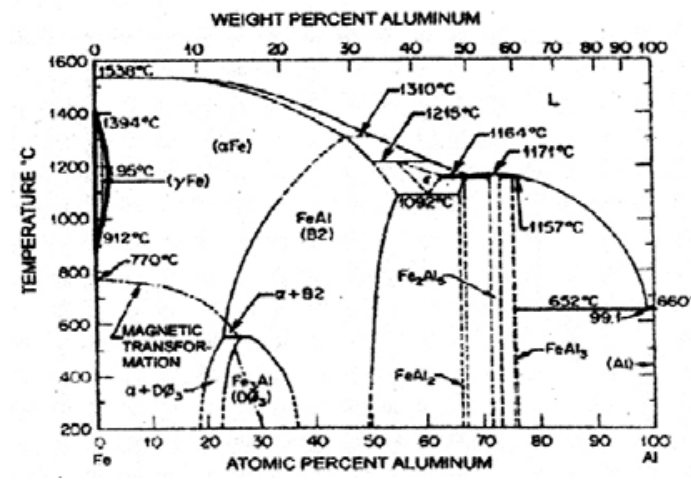

Gambar 3. Diagram Kesetimbangan Fe-Al (Chao, 2002)

\section{METODE PENELITIAN}

Peleburan menggunakan dapur induksi frekwensi tinggi kapasitas $50 \mathrm{~kg}$ milik POLMAN Ceper, Klaten, Jawa Tengah dengan alloying dilakukan di dalam ladle. Bahan baku peleburan menggunakan scrap baja rendah Mn, aluminium murni dan Ferro-karbon. Coran dibuat dalam bentuk ingot dengan ukuran $3 \mathrm{~cm} \times 3 \mathrm{~cm} \times 20 \mathrm{~cm}$. Target komposisi yang akan dicapai adalah Fe1,26\% berat Al-1,05\% berat C. Perhitungan komposisi secara manual dilakukan dengan material balance dengan toleransi kehilangan $\mathrm{Al}$ sebesar 15\%. Ingot paduan Fe-Al-C selanjutnya dipotong menggunakan meta-cut dibentuk menjadi specimen uji tarik berdasarkan standard JIS 2201, spesimen uji kekerasan dan specimen uji korosi dengan ukuran diameter 14 $\mathrm{mm}$ tinggi $10 \mathrm{~mm}$. Proses heat treatment terdiri dari hardening yaitu pemanasan sampai temperatur $900^{\circ} \mathrm{C}$ selama 1 jam dlanjutkan quenching dalam media air. Temper dilakukan pada temperatur $250^{\circ} \mathrm{C}, 300^{\circ} \mathrm{C}, 350^{\circ} \mathrm{C}$, $400^{\circ} \mathrm{C}, 450^{\circ} \mathrm{C}$ selama 1 jam. Uji korosi dilakukan dengan metoda kehilangan berat berdasar standar ASTM G31. Foto struktur mikro dengan mikroskop optik merk Olympus milik Laboratorium Bahan Teknik Jurusan Teknik Mesin Program D3 UGM.

\section{HASIL PENELITIAN DAN PEMBA- HASAN}

\section{Analisis Hasil Uji Struktur Mikro Paduan Fe-1,26Al-1,05C}

Gambar 4 menunjukkan struktur mikro paduan Fe-1,26Al-1,05C as cast, terlihat bahwa struktur paduan terdiri dari ferit dan perlit yang terdistribusi merata dengan jumlah yang hampir seimbang. Terlihat adanya pola dendritik dalam jumlah yang relatif kecil. Perubahan yang mencolok terjadi setelah austenitisasi pada temperatur $900^{\circ} \mathrm{C}$. Struktur ferit mendominasi dengan ukuran butir yang besar-besar sedangkan struktur perlit tersisa sedikit di bagian batas butir ferit (Gambar 5). Sruktur perlit semakin berkurang dengan semakin tinggi temperatur temper dan pada temperatur temper $450^{\circ} \mathrm{C}$ struktur ferit hampir sempurna. Hal ini mem- 
buktikan peran $\mathrm{Al}$ sebagai penstabil struktur ferit pada paduan $\mathrm{Fe}-1,26 \mathrm{Al}-1,05 \mathrm{C}$.

Gambar 4. Struktur Mikro 1,26Al-1,05C d. Temper $350^{\circ} \mathrm{C}$

e. Temper $400^{\circ} \mathrm{C}$ a. Hardening

Ferit

Ferit

\section{Perlit}

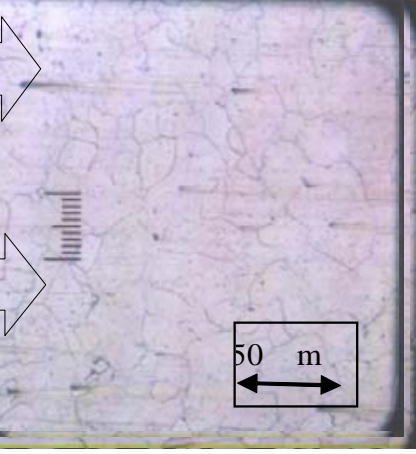

b. Temper $250^{\circ} \mathrm{C}$ f. Temper $450^{\circ} \mathrm{C}$

Gambar 5. Pengaruh Temperatur Temper terhadap Struktur Mikro Paduan

$$
\text { Fe-1,26Al-1,05C }
$$

\section{Analisis Hasil Uji Kekuatan Tarik Paduan Fe-1,26Al-1,05C \\ Hasil uji kekuatan tarik menunjukkan bahwa paduan Fe-1,26Al-1,05C mempunyai kekuatan tarik sebesar 72,51 kg/mm² (Gambar 6) dengan regangan $(\varepsilon)$ sebesar $33,8 \%$. Nilai kekuatan tarik ini cukup tinggi jika dibandingkan dengan kekuatan tarik baja tahan karat feritik Fe-Cr-C yaitu berkisar $45-50 \mathrm{~kg} / \mathrm{mm}^{2}$}


(AZoM ${ }^{\mathrm{TM}}$.com, 2009). Hal ini disebabkan kadar karbon yang tinggi dan adanya senyawa intermetalik Fe-Al yang berperanan dalam peningkatan kekuatan paduan. Setelah hardening terlihat kekuatan tarik meningkat menjadi $82,7 \mathrm{~kg} / \mathrm{mm}^{2}$ yang diikuti dengan penurunan regangan menjadi 25\%. Fenomena ini disebabkan terjadinya perubahan struktur yang sangat mencolok dimana struktur ferit dengan ukuran yang besar lebih mendominasi dikelilingi struktur perlit dengan jumlah yang relatif lebih kecil. Senyawa intermetalik Fe-Al setelah hardening berperanan dalam penurunan regangan. Proses temper akan menurunkan kekuatan. Semakin tinggi temperatur temper kekuatan tarik semakin menurun hingga mencapai nilai minimal sebesar $75,89 \mathrm{~kg} / \mathrm{mm}^{2}$. Fenomena ini disebabkan semakin tinggi temperatur temper maka struktur paduan Fe1,26Al-1,054C akan cenderung menjadi lebih feritik. Transisi getas-ulet paduan $\mathrm{Fe}-1,26 \mathrm{Al}$ 1,054C dapat dilihat dari permukaan patah specimen uji tarik pada Gambar.7.

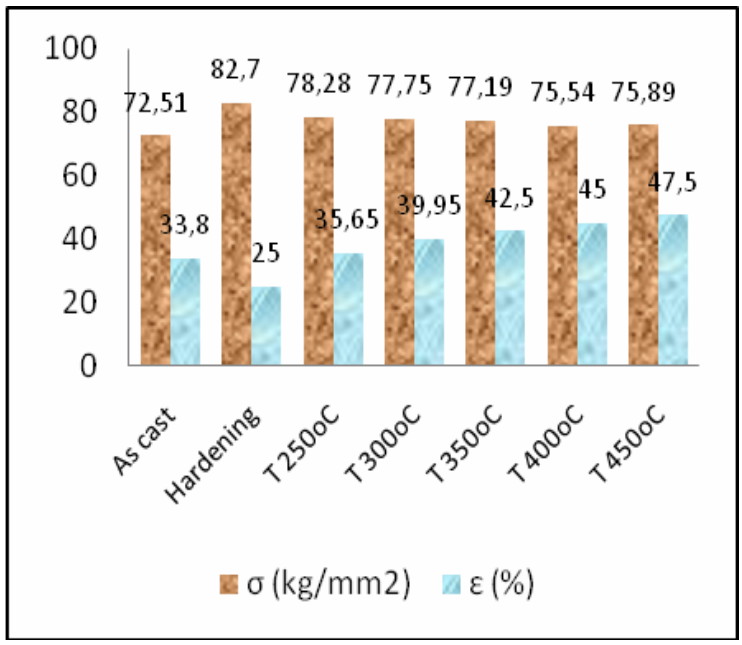

Gambar 6. Pengaruh Temperatur Temper terhadap Kekuatan Tarik dan Regangan Paduan Fe-1,26Al-1,05C

\section{Analisis Hasil Uji Kekerasan Paduan Fe- 1,26Al-1,05C}

Gambar 8. menunjukkan bahwa paduan Fe-1,26Al-1,05C as cast mempunyai nilai

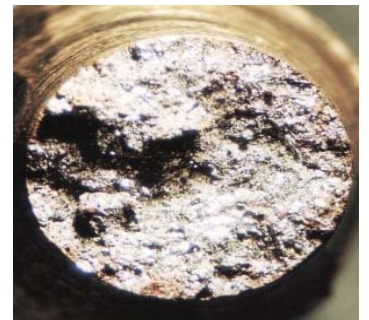

Raw material

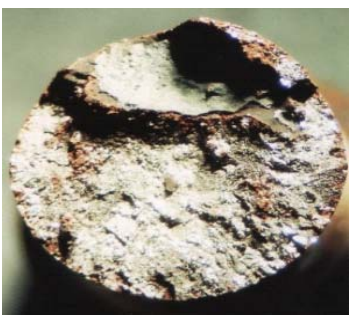

Temper $250^{\circ} \mathrm{C}$

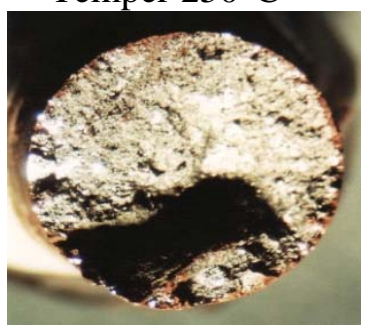

Temper $350^{\circ} \mathrm{C}$

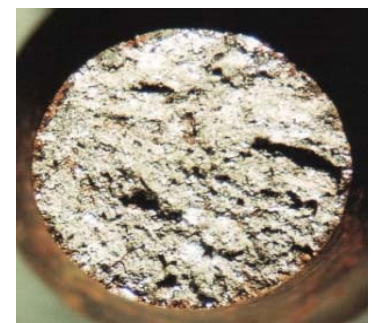

Hardening $900^{\circ} \mathrm{C}$

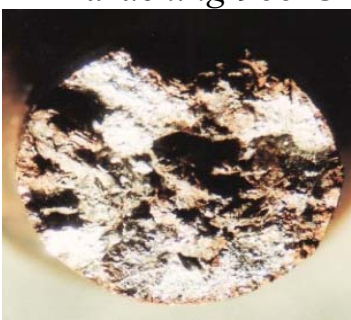

Temper $300^{\circ} \mathrm{C}$

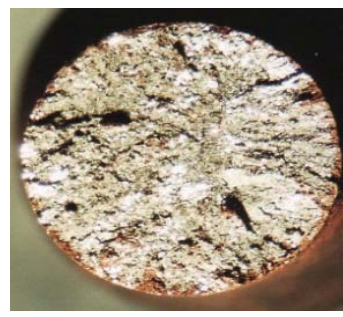

Temper $400^{\circ} \mathrm{C}$

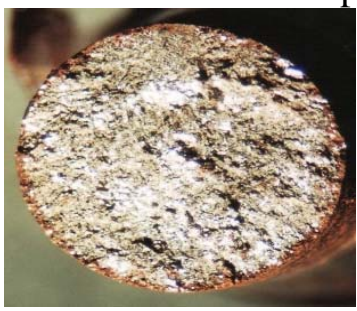

Temper $450^{\circ} \mathrm{C}$

Gambar 7. Makro Permukaan Patah Spesimen Uji Tarik

kekerasan sebesar 219,5 VHN. Nilai kekerasan tertinggi tertinggi terjadi setelah hardening yaitu sebesar 287,1 VHN. Semakin tinggi temperatur temper kekerasan paduan Fe-1,26Al-1,05C semakin menurun hingga mencapai nilai minimal pada temper $450^{\circ} \mathrm{C}$ yaitu sebesar 219,6 VHN. Fenomena ini sesuai dengan fenomena yang terjadi pada struktur struktur mikro paduan Fe1,26Al-1,05C, dimana dengan heat treatment terjadi kecenderungan perubahan struktur menjadi lebih feritik. 


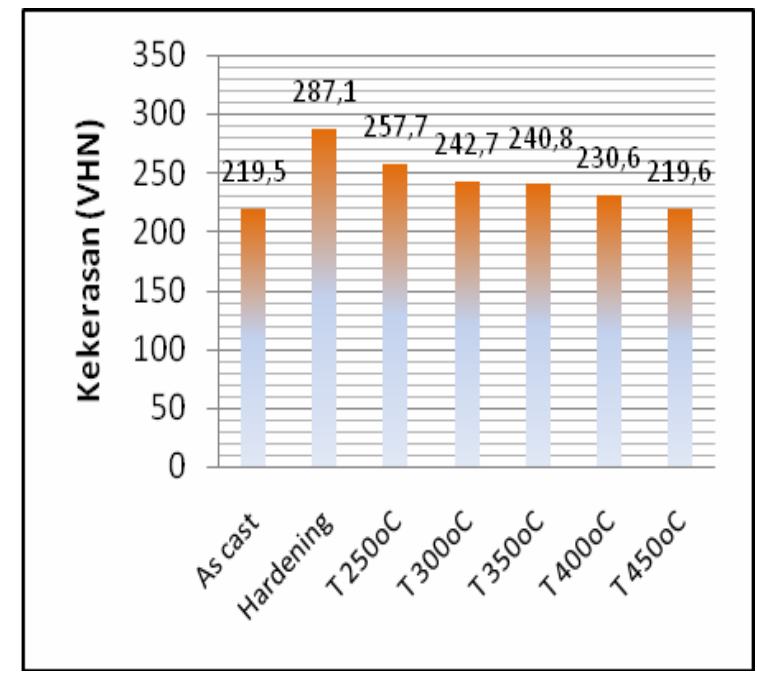

Gambar 8. Pengaruh Temperatur Temper terhadap Kekerasan Paduan Fe-1,26Al-1,05C

\section{Analisis Hasil Uji Ketahanan Korosi Paduan Fe-1,26Al-1,05C}

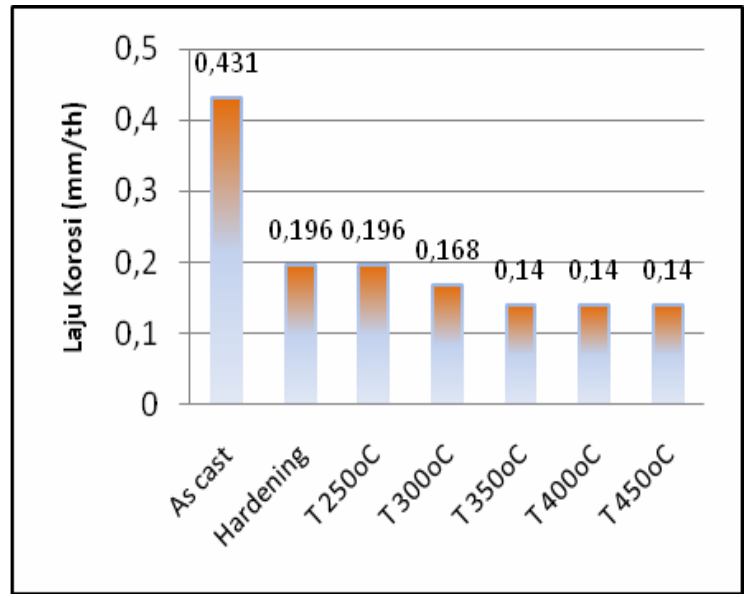

Gambar 9. Pengaruh Temperatur Temper terhadap Ketahanan Korosi Paduan Fe-1,26Al-1,05C

Perhitungan laju korosi dilakukan dengan metoda kehilangan berat. Paduan Fe-1,26Al1,05C as cast mempunyai laju korosi sebesar 0,431 $\mathrm{mm} /$ th termasuk katagori baik berdasarkan Tabel 1 (tabel MPY) (Fontana, 1987). Laju korosi akan semakin menurun dengan heat treatment dan mencapai nilai minimal pada temper $450^{\circ} \mathrm{C}$ dengan laju korosi sebesar $0,14 \mathrm{~mm} /$ th. Jika dianalisis dari perubahan yang terjadi pada struktur mikro akibat proses heat treatment maka penurunan jumlah perlit yang terjadi cenderung menurunkan laju korosi pada paduan Fe-1,26Al-1,05C. Secara keseluruhan berdasarkan tabel 1 laju korosi paduan Fe-1,26Al-1,05C termasuk dalam katagori baik.

Tabel 1. Tingkat Ketahanan Korosi Berdasarkan Harga MPY

\begin{tabular}{|c|c|c|c|c|c|}
\hline \multirow{2}{*}{$\begin{array}{c}\text { Tingkat } \\
\text { ketahanan } \\
\text { korosi }\end{array}$} & \multirow[b]{2}{*}{ MPY } & \multicolumn{4}{|c|}{ Konversi kesatuan-satuan lain } \\
\hline & & $\begin{array}{l}\mathrm{mm} / \\
\text { tahun }\end{array}$ & $\begin{array}{c}\mu \mathrm{m} / \\
\text { tahun }\end{array}$ & $\begin{array}{c}n \mathrm{~m} / \\
\text { tahun }\end{array}$ & $\begin{array}{c}\mathrm{pm} / \\
\text { tahun }\end{array}$ \\
\hline Luar biasa & $<1$ & $<0.02$ & $<25$ & $<2$ & $<1$ \\
\hline Sangat baik & $1-5$ & $0.02-0.1$ & $25-100$ & $2-10$ & $1-5$ \\
\hline Baik & $5-20$ & $0.1-0.5$ & $100-500$ & $10-50$ & $5-20$ \\
\hline Cukup baik & $20-50$ & $0.5-1$ & $500-1000$ & $50-150$ & $20-50$ \\
\hline Kurang baik & $50-200$ & $1-5$ & $1000-5000$ & $150-500$ & $50-200$ \\
\hline $\begin{array}{c}\text { Tidak } \\
\text { dianjurkan }\end{array}$ & $200+$ & $5+$ & $5000+$ & $500+$ & $200+$ \\
\hline
\end{tabular}

Sumber : Fontana, 1987

\section{KESIMPULAN}

1. Struktur paduan Fe-1,26Al-1,05C as cast terdiri dari ferit dan perlit yang terdistribusi merata dan dalam jumlah kecil struktur dendrit. Semakin tinggi temperatur temper struktur berubah menjadi lebih feritik.

2. Kekuatan tarik paduan Fe-1,26Al-1,05C as cast sebesar $72,41 \mathrm{~kg} / \mathrm{mm} 2$ dengan regangan sebesar 33,8\%. Kekuatan tarik maksimal terjadi setelah hardening dan akan menurun dengan semakin tinggi temperatur temper.

3. Nilai kekerasan paduan Fe-1,26Al-1,05C as cast sebesar $219,5 \mathrm{VHN}$. Nilai kekerasan tertinggi terjadi setelah hardening dan akan semakin menurun dengan semakin tinggi temperatur temper.

4. Laju korosi tertinggi terjadi pada paduan Fe1,26Al-1,05C as cast yaitu 0,431 mm/th dan semakin menurun dengan semakin tinggi temperatur temper. Secara keseluruhan laji korosi termasuk katagori baik. 


\section{DAFTAR PUSTAKA}

Avner, H.S., 1987, Introduction to Physical Metallurgy, McGraw-Hill Inc., Singapure.

Baligidad, R.G., Prakash, U., Ramakrishna Rao, V., Rao, P.K., and Ballal N.B., 1996, Effect of Carbon Content on Mechanical Properties of Electroslag Remelted Fe3Al Based Intermetallic alloys, Vol. 36, No. 12, 1453-1458.

Baligidad, R.G., Prakash, U., and Radha Krishna, 1998, Effect of Carbon Addition on Structure and Mechanical Properties of Electroslag Remelted Fe-20wt.\%Al alloy, Vol. 249, No. 1-2, 97-102.

Chao, Y.C., and Liu, C.H., 2002, Effect of Mn Content on the Micristructure and Mechanical Properties of Fe-10Al-xMn-1.0C Alloy, Materials Transactions, Vol. 3, No. 10, pp. 2635-2642.

Davidson, R.M., DeBold, T. dan Johnson, M.J, 1988, Corrosion of Stainless Steel, dalam ASM Handbook, Metals Park, Ohio

Environmentalchemistry.com, 2008, Environmental, Chemistry \& Hazardous Materials News, Careers \& Resources, Periodic Table of Elements.

Fontana, G.M., 1988, Corrosion Engineering, 3th ed., McGraw Hill Inc., Singapore.

Frommeyer, 2000, Physical and Mechanical Properties of Iron-Aluminium-(Mn-Si) Lightweight Steels, The 1999ATS International Steelmaking Conference, Paris. Sec.4.

Honeycombe, R.W.K. dan Bhadeshia, H.K.D.,1995, Steel Microstructure and Properties, $2^{\text {nd }}$ ed., Edward Arnold, London.

Huang, B.X., Wang, X.D., Rong,Y.H., Wang, L., and Jin, L., 2006, Mechanical Behavior and Martensitic Transformation of an Fe-Al-Si-Al-Nb Alloy, Materials Science and Engineering A, Vol. 438-440, p. 306-311.

Kobayashi, S., Zaefferer, S., Schneider, A., Raabe, D., and Frommeyer, G., 2005, Optimisation of Precipitation for Controlling Recrystallization of Wrought Fe3Al Based Alloys, Intermetallics, 13, 1296-1303.

Leslie, T., 1983, The Physical Metallurgi of Steels, John Willey and Sons Inc., New York.

Prakash, U. Buckley, R.A., Jones, H. and Sellars, C.M., 1991, Structure and Properties of Ordered Intermetallics Based on the Fe-Al System, ISIJ Int., vol 31, no. 10, 1113-1126.

Shackelford, J.F., 1992, Introduction to Material Science for Engineers, 3th ed., McMillan Publishing Company, New York.

Sikka, V.K., Viswanathan, S., and McKamey, C.G., 1993, in 'Structural Intermetallic', (ed. R. Darolia et al.), Warrendale, PA, TMS. pp. 483-491

Tjong, S.C., 1986, Stress Corrosion Cracking behavior of the duplex Fe-10Al-29Mn-0,4C alloy in $20 \% \mathrm{NaCl}$ solution at $100^{\circ} \mathrm{C}$, Journal of Material Science, Vol. 21, Hal.: 11661170 
Wang, S., Zhang, H., dan Chen, S.J., 2000, Experiment on Fe-Al-Mn Deoxidizing and Alloying of Low-carbon Aluminium Killed Steel, Journal Iron Steel Vanadium Titanium, Vol. 21, No. 4., hal. 44-49. 